\title{
Duplicación de la vesícula biliar
}

\author{
Nicolás García $A^{1}$., Elizabeth Prado $A^{2}$.
}

1. Residente de Radiología, Universidad de los Andes. Santiago - Chile. nicolasgarciaa@gmail.com

2. Servicio de Radiología, Clínica Santa María. Santiago - Chile.

\section{Gallbladder Duplication}

\begin{abstract}
Gallbladder duplication is a rare congenital anomaly and, like other biliary malformations, is associated with an increased risk of complications in the laparoscopic cholecystectomy. We present a case of a woman consulting in the emergency department for clinical symptoms compatible with acute cholecystitis. An abdominal ultrasound is performed confirming the clinical suspicions, observing the typical findings. Pathological dilatation of the extrahepatic biliary tract is also confirmed, therefore she is evaluated with MR cholangiography, which also confirms signs compatible with acute cholecystitis; the presence of a cystic formation of saccular morphology in an intrahepatic location was identified, with the same structure as the gallbladder, but smaller in size and with a duct of its own that drained into the common hepatic duct independently to the cystic duct of the inflamed vesicle.
\end{abstract}

Keywords: Gallbladder, malformation, cholelithiasis.

Resumen. La duplicación de la vesícula biliar es una anomalía del desarrollo poco frecuente, y al igual que otras malformaciones de la vía biliar, se asocia a un mayor riesgo de complicaciones en la colecistectomía laparoscópica. Se presenta un caso de una mujer que consulta en el servicio de urgencia por cuadro clínico compatible con colecistitis aguda. Se realiza una ecografía abdominal que confirma la presunción clínica, observándose los hallazgos típicos. Se constata además dilatación patológica de la vía biliar extrahepática, por lo que se evalúa con colangiorresonancia, que además de confirmar los signos compatibles con la colecistitis aguda, se identificó la presencia de una formación quística de morfología sacular en situación intrahepática, de igual morfología que la vesícula biliar, pero de menor tamaño y con un conducto propio que drenaba al conducto hepático común en forma independiente al conducto cístico de la vesícula inflamada.

Palabras clave: Vesícula biliar, malformación, colelitiasis.

García N., et al. Duplicación de la vesícula biliar. Rev Chil Radiol 2017; 23(1): 41-44.

Correspondencia: Nicolás García A. / nicolasgarciaa@gmail.com

Trabajo recibido el 22 de febrero de 2016. Aceptado para publicación el 17 de marzo de 2017.

\section{Introducción}

La duplicación de la vesícula biliar es una anomalía rara del desarrollo, con una incidencia reportada de aproximadamente un caso en 4.000 autopsias'1.

Las anomalías congénitas y las variaciones anatómicas de la vesícula y vías biliares se asocian con un mayor riesgo de complicaciones en la colecistectomía laparoscópica, sobre todo relacionadas con lesiones iatrogénicas de la vía biliar. Por esto el estudio preoperatorio con imágenes juega un rol importante en su pesquisa, permitiendo al cirujano realizar una adecuada planificación quirúrgica.

A continuación, se presenta el caso de una paciente con duplicación de vesícula biliar diagnosticada por colangiorresonancia.

\section{Caso clínico}

Paciente mujer, de 66 años, consulta en el Servicio de Urgencia por un cuadro de tres días de evolución de dolor abdominal epigástrico, tipo cólico, asociado a la coloración amarilla de las escleras. Al examen físico se encontraba levemente deshidratada, ictérica, taquicárdica (148 Ipm), temperatura $37,6^{\circ} \mathrm{C}$, normotensa. El abdomen se describió como levemente distendido, blando, depresible, sensible a la palpación en el hipocondrio derecho, con el signo de Murphy 
positivo. Dentro del estudio de laboratorio destacaba un patrón colestásico, con elevación de la bilirrubina total, fosfatasas alcalinas, GGT, y leve elevación de GOT y GPT. La PCR se encontraba elevada, con un hemograma normal.

Se indicó estudio inicial con ecografía abdominal, con la sospecha clínica de colecistitis aguda en evolución. El examen ultrasonográfico del abdomen mostró una vesícula sobredistendida, con paredes engrosadas y con un cálculo impactado en el bacinete (Figura 1), compatible con un cuadro de colecistitis aguda. De manera adicional, se constató una leve dilatación de la vía biliar extrahepática, sin lograr visualizar un factor obstructivo evidente (Figura 2).

Se solicitó estudio con colangiorresonancia, donde se confirman los signos ya visualizados con ultrasonido compatibles con la colecistitis aguda (Figura 3), se identificó la presencia de coledocolitiasis distal (Figura 4) y en las secuencias colangiográficas se constató la presencia de una formación quística de morfología sacular en situación intrahepática, de

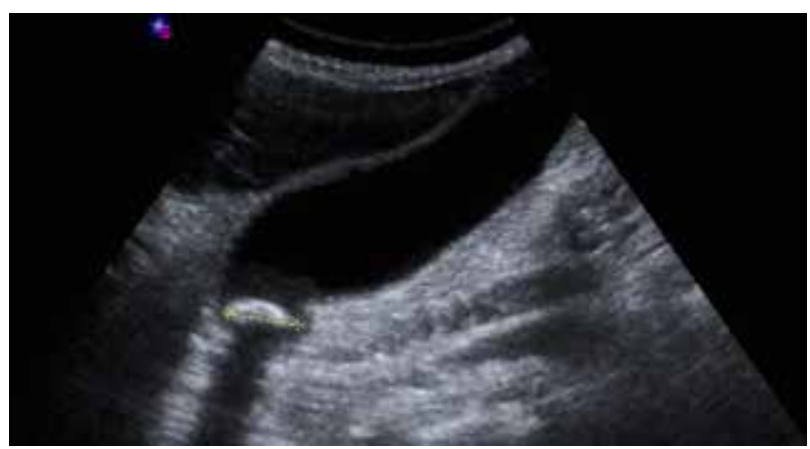

Figura 1. Visión ecográfica de la vesícula biliar sobredistendida, de paredes engrosadas y con cálculo impactado en el bacinete, compatible con colecistitis aguda.

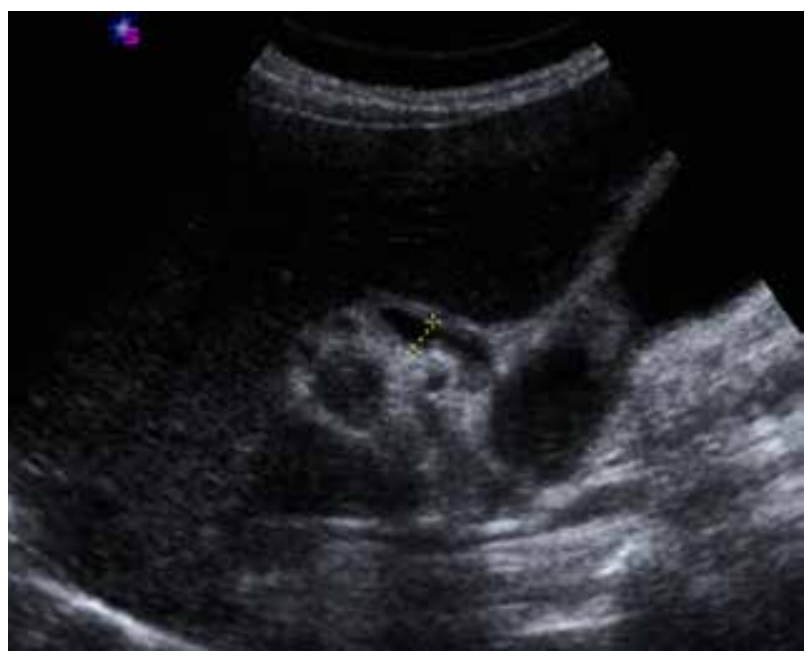

Figura 2. Visión ecográfica que muestra la dilatación de la vía biliar extrahepática, con un diámetro máximo de 7,2 mm.
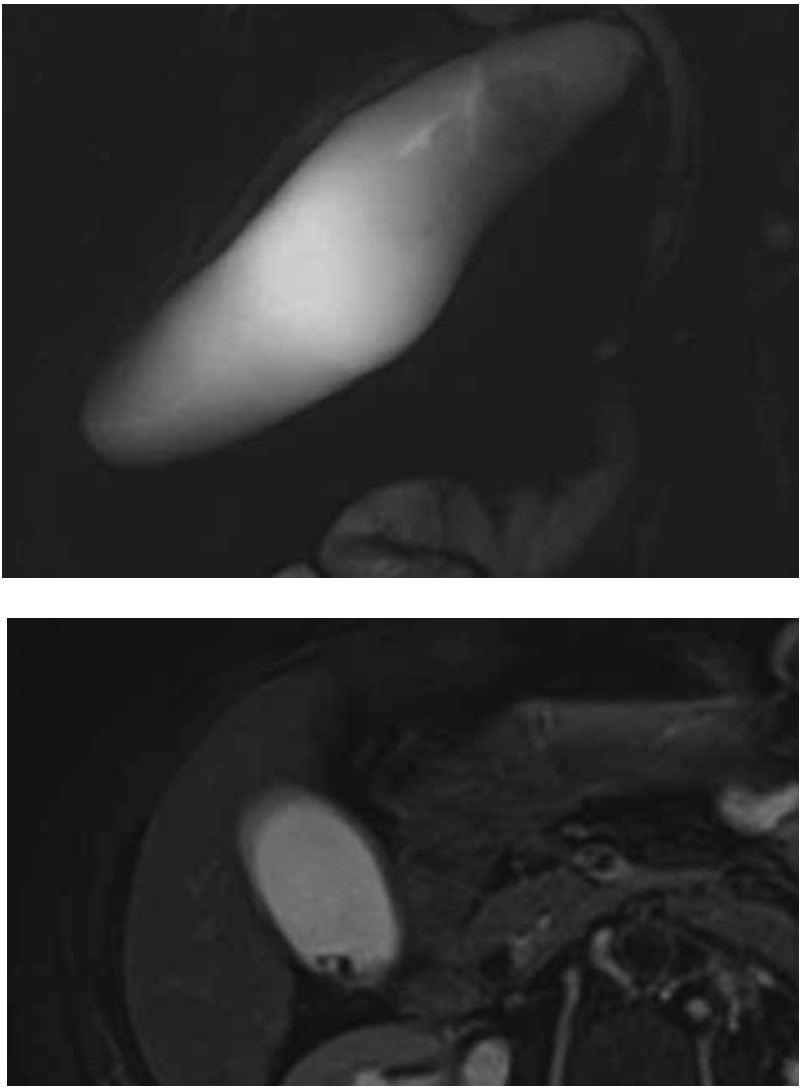

Figura 3. a. Secuencia colangiográfica. Sobredistensión de la vesícula biliar, asociado a líquido perivesicular. $\boldsymbol{b}$. Corte axial de secuencia ponderada en T2 con saturación grasa. Engrosamiento de la pared vesicular, asociado a colelitiasis.

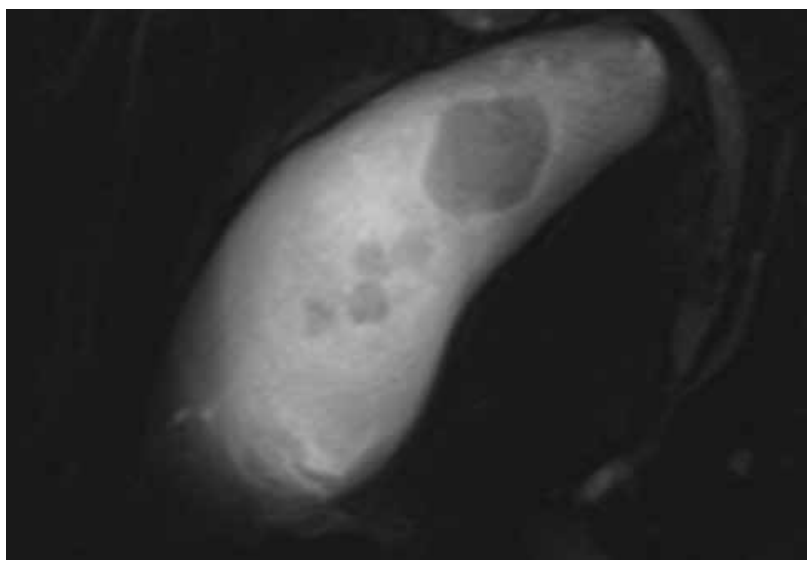

Figura 4. Secuencia colangiográfica. Defectos de llene hipointensos de distinto tamaño, polifacetados, en vesícula biliar y colédoco distal, compatible con litiasis.

igual morfología que la vesícula biliar, pero de menor tamaño y con un conducto propio que drenaba al conducto hepático común en forma independiente al conducto cístico de la vesícula inflamada, hallazgos compatibles con una duplicación de la vesícula biliar (Figura 5). No se visualizaron imágenes compatibles con cálculos en su interior. 

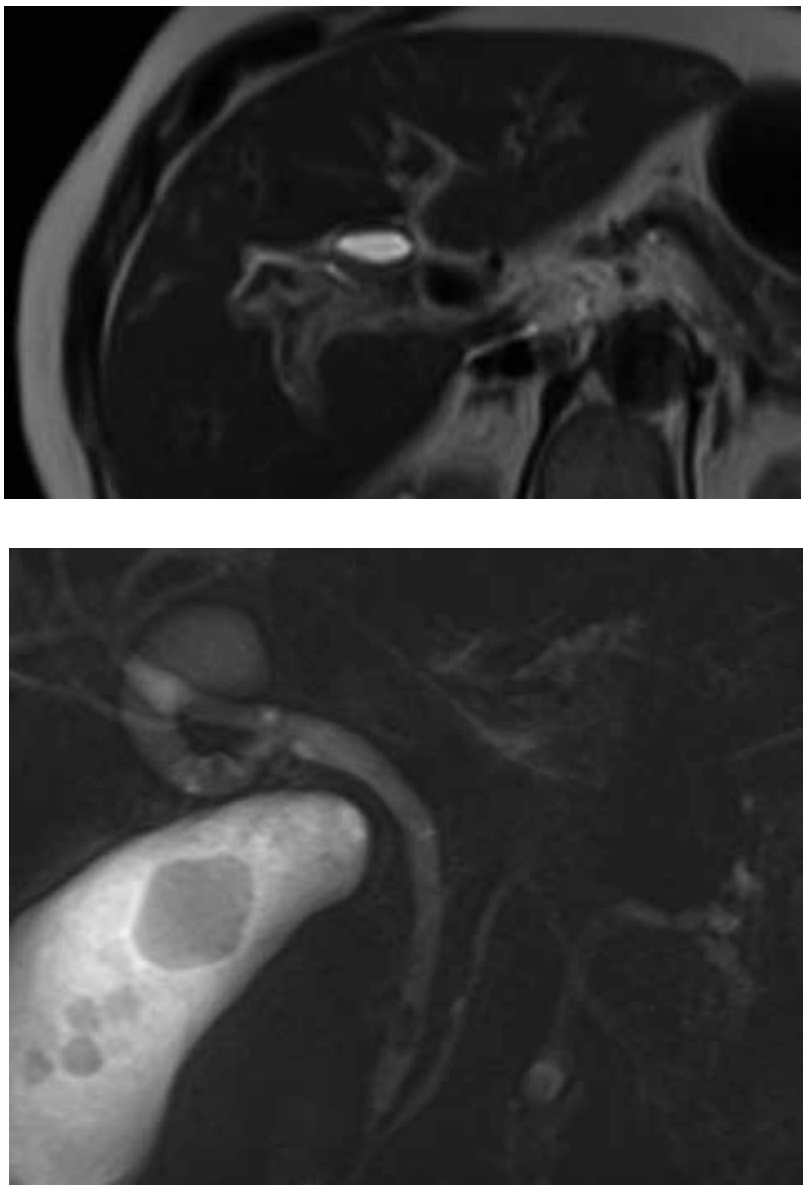

Figura 5. a. Corte axial de secuencia ponderada en T2. Formación quística sacular en situación intrahepática. b. Secuencia colangiográfica. Vesícula duplicada, con coducto cístico propio que drena en forma independiente en el conducto hepático común.

La paciente fue sometida a una colecistectomía laparoscópica, en donde la vesícula duplicada no pudo ser visualizada, por lo que se extrajo sólo la vesícula inflamada, y se realizó una papilotomía endoscópica, ambos procedimientos realizados sin incidentes.

\section{Discusión}

Embriológicamente, la vesícula biliar se origina en la cuarta semana del desarrollo, a partir de un brote que emerge desde el conducto biliar, que corresponde a un segmento de tejido endodérmico que une el intestino anterior con el primordio hepático. Inicialmente es sólida, y alrededor de la séptima semana se canaliza, y el pedículo pasa a formar el conducto cístico. A partir de la $12^{2}$ semana, comienza la síntesis hepática de bilis, iniciándose la circulación a través de la vía biliar hacia el intestino'.

La duplicación de la vesícula biliar es poco frecuente, con una incidencia reportada de alrededor de un caso en 4.000. Boyden ${ }^{2}$ reportó dos casos de duplicación de vesícula biliar en 9.221 autopsias. Hess ${ }^{3}$, por otro lado, encontró un caso en 4.000 pacientes operados. Se trata de una patología que no posee síntomas específicos, y las alteraciones no son más frecuentes que en pacientes con vesícula única ${ }^{4,5}$. Por lo tanto, la frecuencia de entidades patológicas es similar, siendo la colelitiasis la complicación más frecuente, pudiendo desarrollarse tanto en una como en ambas vesículas ${ }^{6,7}$. Por otro lado, la duplicación de la vesícula biliar no se asocia a la presencia de otras anomalías del desarrollo?.

Boyden ${ }^{1}$ clasificó morfológicamente las duplicaciones de la vesícula biliar en tres tipos. La forma "tipo Y" corresponde a dos vesículas adheridas ocupando la misma fosa, con dos conductos císticos separados que se fusionan antes de desembocar en el conducto hepático común. Cada vesícula presenta su arteria cística independiente ${ }^{8}$. La forma "tipo H" está constituida por dos vesículas separadas, cada una con su conducto cístico que drena en forma independiente en el conducto hepático común, situación en la que ambas vesículas presentan arterias císticas independientes. El caso presentado corresponde a esta (tipo H). Por último, el tercer tipo descrito por Boyden corresponde a las vesículas bilobuladas o septadas, en donde la vesícula biliar se encuentra dividida por un tejido fibroso o fibromuscular, sin mucosa en el tabique. En este caso, existe un solo conducto y una arteria cística.

Es importante reconocer la duplicación de la vesícula biliar en los estudios preoperatorios, de manera de prevenir posibles complicaciones quirúrgicas y eventuales re-intervenciones quirúrgicas. Dado que la mayoría de las complicaciones iatrogénicas de la colecistectomía laparoscópica se deben a la falta de diagnóstico de variaciones anatómicas de la vía biliar, la documentación pre-operatoria de la anatomía cobra mayor importancia.

La ecografía es el estudio inicial para la evaluación de la vesícula y vías biliares. Sin embargo, presenta algunas desventajas, ya que no siempre permite diagnosticar malformaciones en la vesícula biliar. Varias entidades pueden presentarse de manera similar en la ecografía, como la vesícula plegada, quistes del colédoco, vesícula con gorro frigio, líquido pericolecístico, divertículo vesicular, adenomiomatosis focal, entre otros ${ }^{9}$. Si bien la ecografía puede demostrar en la mayoría de los casos el grosor de la pared, patología intraluminal y el número de vesículas, no tiene buen rendimiento diagnóstico en la descripción de la anatomía exacta del árbol biliar ${ }^{10}$.

La colangiorresonancia permite demostrar la morfología de la vía biliar en el pre-operatorio, permitiendo una adecuada planificación quirúrgica en casos de variaciones anatómicas, por lo tanto, reducir el riesgo de lesiones iatrogénicas en las colecistectomías laparoscópicas. Además, cuenta con la ventaja de que es una técnica no invasiva, no usa radiación 
ionizante y es operador independiente.

La colangiopancreatografía endoscópica retrógrada es una alternativa a la colangiorresonancia. También permite la visualización del árbol biliar y sus variaciones anatómicas. Sin embargo, se trata de un procedimiento invasivo, con morbilidad reportada hasta en un $7 \%$ de los casos ${ }^{11}$, por lo que se reserva para casos en donde se necesite realizar algún procedimiento terapéutico.

En general, cuando una de las dos vesículas se hace sintomática, se recomienda la resección de ambas, ya que se han reportado re-intervenciones quirúrgicas por complicaciones en pacientes con duplicaciones no removidas durante la primera cirugía ${ }^{12}$. En el caso presentado, la segunda vesícula no pudo ser visualizada, probablemente debido a su localización intrahepática, por lo que el equipo quirúrgico decidió preservarla antes de realizar una cirugía mayor, sobre todo considerando que la segunda vesícula no presentaba patología litiásica.

\section{Bibliografía}

1. Sadler, TW. Langman's Medical Embriology. 12th edition. Philadelphia: Wolters Kluwer Health/Lippincott Williams \& Wilkins 2012; 217-220.

2. Boyden EA. The accesory gall-bladder-an embryological and comparative study of aberrant biliary vesicles occurring in man and the domestic mammals. Am J Anat 1926; 38: 177-231.

3. Hess W. Enfermedades de las vías biliares y del páncreas. 3a edición. Barcelona: Editorial Científicomédica 1963; 3-37.

4. Harlaftis N, Gray SW, Olafson RP, Skandalakis JE. Three cases of unsuspected double gallbladder. Am Surg 1976; 3: 178-180.

5. Harlaftis N, Gray SW, Olafson RP, Skandalakis JE. Multiple gallbladders. Surg Gynecol Obst 1977; 145: 928-934.

6. Díaz MJ, Fowler W, Hnatow BJ. Congenital gallbladder duplicaton: preoperative diagnosis by ultrasonography. Gastrointest Radiol 1991; 16: 198-200.

7. Cueto García J, Webwr A, Berry FS, Tatz BT. Double gallbladder treated successfully by laparoscopy. J Laparoendosc Surg 1993; 3: 153-155.

8. Senecail B, Textier F. Anatomic variability and congenital anomalies of gallbladder: ultrasonographic study of 1823 patients. Morphologie 2000; 84: 35-39.

9. Ozgen A, Akata D, Arat A. Gallbladder duplication: imaging findings and differential considerations, Abdom. Imaging 1999; 24: 285-288.

10. Gocmen R, Yesilkaya Y. Imaging findings of gallbladder duplication due to two cases: case report and review of literature. Med Ultrason $2012 \mathrm{Dec}$; 14(4): 358-360.

11. Katabathina V, Dasyam A, Dasyam N, Hosseinzadeh K. Adult bile duct strictures: role of MR imaging and MR cholangiopancreatography in characterization. Radiographics 2014 May-Jun; 34(3): 565-586.

12. Elorza J, López S, Espinoza B, Izquierdo F, Carriel V. Duplicación de la vesícula biliar: Vesícula doble de tipo Y operada. Reporte de un caso. Rev Chil Cir 2009 Jun; 61(3): 275-278. 